\title{
DISSEMINATION OF MALIGNANT TUMORS AFTER VIDEO-ASSISTED THORACIC SURGERY: A REPORT OF TWENTY-ONE CASES
}

Robert J. Downey, MD

Patricia McCormack, MD

Joseph LoCicero III, MD

The Video-Assisted Thoracic

Surgery Study Group

\begin{abstract}
Video-assisted thoracic surgical techniques are widely used for biopsy and resection of thoracic tumors, but studies of long-term outcomes have not been reported. Dissemination of tumor by these techniques is a potential hazard. Therefore we surveyed the surgical members of the Video-Assisted Thoracic Surgery Study Group to determine whether tumor implants thought to be directly related to video-assisted techniques had occurred. Surgeons reported 21 cases. The sites of recurrence were the incision $(n=$ 14), pulmonary staple line $(n=2)$, pleura $(n=2)$, both staple line and incision $(n=1)$, both pleura and incision $(n=1)$, and both pleura and staple line $(n=1)$. Review of these cases illustrates the pitfalls of present video-assisted techniques for malignant tumors of the thorax. ( $J$ Thorac Cardiovasc Surg 1996;111:954-60)
\end{abstract}

A fter the introduction of video-assisted thoracic surgery (VATS) in late 1980s, physicians, surgeons, and patients rapidly adopted the technique for biopsy and, occasionally, for curative resection of malignant tumors of the thorax. Despite the attractiveness of this approach, little long-term information exists to validate its widespread adoption.

One limitation of the VATS technique is that tumors are often visualized only as a distortion of the visceral or parietal surface and are palpable only with the fingertips. This limited ability to clearly define tissue margins has raised concerns that VATS techniques may be more likely to disrupt and disseminate malignant tumors than the type of manipulation that occurs during an open thoracotomy. ${ }^{1} \mathrm{~A}$ recent case report described the implantation of a malignant tumor within chest wall incisions during a seemingly uneventful and complete resection of a single nodule of metastatic adenocarcinoma. ${ }^{2}$ Subsequently, to determine whether other general thoracic surgeons skilled in VATS techniques have

From the Divisions of Thoracic Surgery, Memorial Sloan-Kettering Cancer Center, New York, N.Y., and New England Deaconess Hospital, Boston, Mass.

Received for publication March 24, 1995.

Accepted for publication June 12, 1995.

Address for reprints: Robert J. Downey, MD, Division of Thoracic Surgery, Memorial Sloan-Kettering Cancer Center, 1275 York Ave., New York, NY 10021.

Copyright (C) 1996 by Mosby-Year Book, Inc.

$0022-5223 / 96 \$ 5.00+0 \quad \mathbf{1 2 / 1 / 6 7 0 3 5}$ encountered this potentially serious problem, we surveyed 55 members of the Video-Assisted Thoracic Surgery Study Group (VATSSG). Surgeons were asked to submit any cases in which the manner of recurrence of malignant disease suggested dissemination of the tumor at the time of a VATS procedure.

\section{Methods}

The VATSSG is composed of surgeons whose practices include at least $50 \%$ general thoracic surgery. ${ }^{3}$ Contact with the members was by either telephone or mail. All positive responses were confirmed in writing. The questionnaire began: "Have you participated in the care of any patient who underwent a VATS procedure for the biopsy or resection of a thoracic malignancy and whose subsequent course suggests either subcutaneous implantation, pleural seeding, or staple-line recurrence of the malignancy?" If this question was answered affirmatively, further data were solicited: the date of the thoracoscopic procedure, the preoperative diagnosis, the type of procedure, the use of adjuncts to localize the nodule, the use of techniques to isolate the surgical specimen from the subcutaneous tissues, the histologic diagnosis, and any surgical procedures, such as thoracotomy and lobectomy, that were done after the wedge biopsy. Also, information on the date of diagnosis of the recurrence, the symptoms of recurrence, and the location, treatment, and outcome of the recurrence were collected.

\section{Results}

Forty-eight of 55 surgeons $(87 \%)$ replied to inquiries. Sixteen surgeons reported a total of 21 cases that fit the pattern of tumor progression or recurrence suggesting dissemination of malignant disease 
Table I. Primary lung cancers

\begin{tabular}{llcl}
\multicolumn{1}{c}{$\begin{array}{c}\text { Histologic } \\
\text { type }\end{array}$} & \multicolumn{1}{c}{$\begin{array}{c}\text { Site of } \\
\text { recurrence }\end{array}$} & $\begin{array}{c}\text { Time to } \\
\text { recurrence } \\
(\text { mo })\end{array}$ & Outcome \\
\hline Adenocarcinoma & Pleura/incision & 3 & Alive \\
Adenocarcinoma & Incision & 18 & Alive \\
Adenocarcinoma & Pleura & 4 & Dead \\
Adenocarcinoma & Incision & 3 & Dead \\
Adenocarcinoma & Incision & 11 & Dead \\
Adenocarcinoma & Incision & 23 & Dead \\
Squamous & Suture line & 12 & Alive \\
Squamous & Suture line & 14 & Alive \\
Squamous & Incision & 4 & Dead \\
\hline
\end{tabular}

Table II. Disease metastatic to lung

\begin{tabular}{llcc}
\hline \multicolumn{1}{c}{$\begin{array}{c}\text { Histologic } \\
\text { type }\end{array}$} & \multicolumn{1}{c}{$\begin{array}{c}\text { Site of } \\
\text { recurrence }\end{array}$} & $\begin{array}{c}\text { Tecurrence } \\
(\text { mo })\end{array}$ & Outcome \\
\hline Spindle cell sarcoma & $\begin{array}{c}\text { Suture line and } \\
\text { incision } \\
\text { Suture line and } \\
\text { Uterus }\end{array}$ & 2 & Alive \\
Medullary thyroid & Incision & 8 & Alive \\
Melanoma & Pleura & 6 & Alive \\
Colon adenocarcinoma & Incision & 1 & Alive \\
\hline
\end{tabular}

at the time of thoracoscopy. One surgeon, after completing a questionnaire, published the material as a detailed case report ${ }^{4}$; this case is included in this report.

The histologic characteristics, site of recurrence, time to recurrence, and outcome at the time of the surgeon's report are summarized in Tables I to IV.

The initial operations were performed between June 1987 and February 1994. The time from the original thoracoscopic procedure to diagnosis of recurrence ranged from 2 weeks to 29 months (mean 7.6 months, median 4 months).

Aids to locate tumors at the time of the initial operation included preoperative needle localization $(n=1)$, digital palpation $(n=4)$, none $(n=9)$, and not reported $(n=7)$. Techniques to isolate tissue removed from contact with the subcutaneous tissues, such as disposable ports or bags, were used in seven patients, not used in nine, and not reported in five. In the procedures in which the preoperative diagnosis was either an indeterminate nodule $(n=$ 12 ) or a known primary lung tumor $(n=1)$, eleven reports stated that the procedure was not converted to an open thoracotomy and lobectomy, and two reports gave no information. The preoperative diagnoses in the eight other cases were mediastinal masses $(n=2)$ or pleural effusions $(n=6)$.
Table III. Mesotheliomas

\begin{tabular}{lcc}
\hline $\begin{array}{c}\text { Site of } \\
\text { recurrence }\end{array}$ & $\begin{array}{c}\text { Time to } \\
\text { recurrence }(\mathrm{mo})\end{array}$ & Outcome \\
\hline Incision & 2 & Dead \\
Incision & 2 & Alive \\
Incision & 29 & Alive \\
Incision & 0.5 & Alive \\
Incision & 1 & Alive \\
\hline
\end{tabular}

Table IV. Other histologic types

\begin{tabular}{cccc}
$\begin{array}{c}\text { Histologic } \\
\text { type }\end{array}$ & $\begin{array}{c}\text { Site of } \\
\text { recurrence }\end{array}$ & $\begin{array}{c}\text { Time to } \\
\text { recurrence } \\
(\text { mo })\end{array}$ & Outcome \\
\hline $\begin{array}{c}\text { Small-cell carcinoma } \\
\text { of lung }\end{array}$ & Incision & 8 & Alive \\
$\begin{array}{c}\text { Esophageal squamous } \\
\text { carcinoma }\end{array}$ & Incision & 4 & Alive \\
\hline
\end{tabular}

Recurrence was first suspected on the basis of a painless subcutaneous mass in eleven patients, a subcutaneous mass and effusion in one, a painful subcutaneous mass in four, dyspnea in one, and an asymptomatic radiologic finding in four. Treatments to control recurrence included resection in five, resection and radiotherapy in two, resection and chemotherapy in two, chemotherapy in two, pleurodesis in two, radiotherapy in three, radiotherapy and chemotherapy in one, and supportive care alone in one; this information was not reported in three.

\section{Representative case reports}

CASE 1 . In early 1992, as part of a routine physical examination, a 62-year-old retired sheet metal worker had a chest radiograph and computed tomogram (Fig. 1), which showed a mass in the right lung. Bronchoscopic washings demonstrated cells consistent with squamous cell carcinoma. Results of the preoperative evaluation were all within normal limits, including physical examination, pulmonary function tests, arterial blood gas values with the patient breathing room air, bone scan, and computed tomograms of the brain. No evidence of metastatic disease was detected. Mediastinoscopic examination revealed no abnormalities. The patient underwent a resection of the posterior portion of the anterior segment of the right upper lobe by means of VATS techniques. The mass was removed through an incision in the right fifth intercostal space in the anterior axillary line. The pathologic diagnosis was "moderately poorly differentiated squamous carcinoma" which "approximates but does not infiltrate 


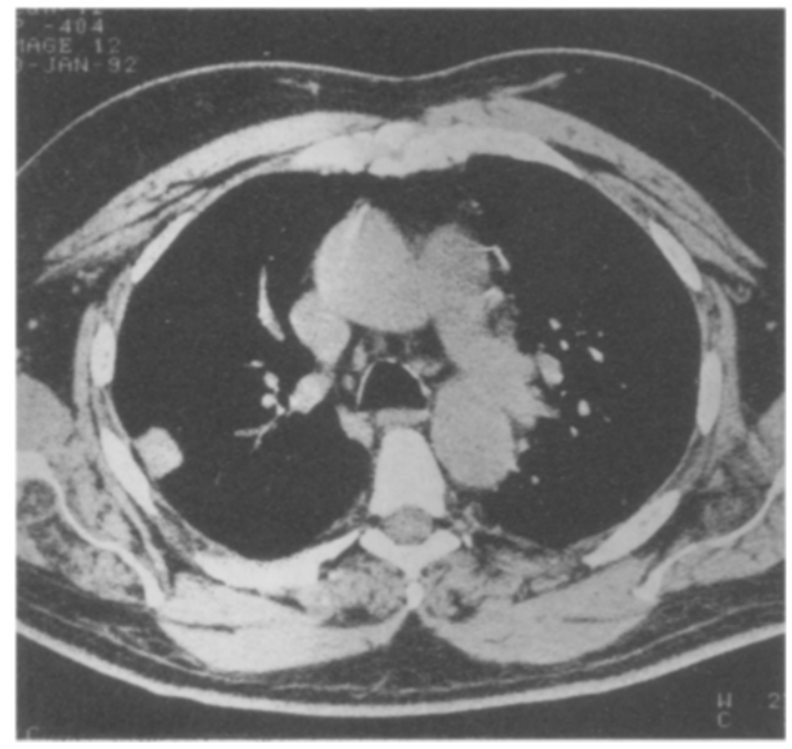

Fig. 1. Preoperative thoracic computed tomogram demonstrating a mass in the peripheral right midlung field. No pleural effusion or adenopathy noted.

the pleural surface." The parenchyma at the stapled margin did not involve tumor.

The initial recovery was uneventful. However, during the fourth postoperative month, complaints of persistent pain in the anterior chest wall led to computed tomograms of the chest (Fig. 2), which demonstrated a $3 \mathrm{~cm}$ mass in the region of the anterior incision and a pleural effusion. Information regarding the cytologic characteristics of the effusion is not available. The chest wall was excised, including portions of two ribs and the tract. Pathologic examination located three nodules of squamous cell carcinoma: one in the intercostal soft tissue and two in the subcutaneous tissues, suggestive of metastases from the primary lung tumor. Postoperative radiotherapy was given to the right anterior chest wall. Nevertheless, by the eighth postoperative month, physical examination and chest computed tomograms (Fig. 3) showed a recurrent soft tissue mass medial and anterior to the area of chest wall resection, as well as probable spread within the lung parenchyma and the pleural space. Because of the extensive operation necessary to resect the mass and the deteriorating respiratory reserve of the patient, the risk of resection for cure was prohibitive. Chemotherapy (mitomycin/cisplatin/vinblastine) was initiated.

CASE 2. A 38-year-old woman who received mantle irradiation for stage IA Hodgkin's disease in
1979 noted the development of a chronic cough in late 1993. Chest radiographs and computed tomograms demonstrated multiple bilateral lung parenchymal nodules. VATS was performed on the right side with wedge excision of two nodules from the right upper lobe and one from the right lower lobe of the lung and a pleural biopsy. The pathology report was "spindle and round cell sarcoma in several foci" consistent with metastatic spread from an unknown primary tumor. Further evaluation revealed a sarcoma of the left leg. Within 8 weeks of thoracoscopic resection, a massive recurrence developed around the staple line and in the chest wall (Fig. 4). Reoperation including a right upper lobectomy and partial chest wall resection was performed.

CASE 3. A new right lung mass developed in a 68-year-old woman (Fig. 5) 2 years after resection of a colon adenocarcinoma. Thoracoscopic wedge excision of the lung nodule revealed metastatic adenocarcinoma consistent with a primary tumor of the colon. Eight months after the thoracoscopic procedure, partial resection of the right chest wall revealed adenocarcinoma, histologically identical to the lung tumor, eroding a rib under the thoracoscopy incision (Fig. 6).

\section{Discussion}

Until now, local dissemination and implantation of most malignant tumors of the thorax to thoracotomy incisions have been infrequent. Only mesothelioma invades incisions, pleural biopsy sites, or chest tube insertion sites with any frequency. ${ }^{5}$ Implantation of other histologic types of thoracic tumors is rare. Although case reports have been published of implantation metastasis as a result of needle biopsy of other histologic types of lung tumors, ${ }^{6,7}$ the risk is low. In one report, only one case occurred in 1264 positive biopsy results over a period of 14 years. ${ }^{8}$ Intraoperative pleural washings obtained after pulmonary resections through a thoracotomy incision suggest that microscopic spillage of tumor cells does occur, most commonly during the lysis of tumor adhesions to the parietal pleural surface. ${ }^{9,10} \mathrm{Al}-$ though no reports have been published of small primary or secondary malignant lung tumors being implanted in a thoracotomy incision after lung resection, larger intrathoracic malignant tumors would seem to be at greater risk for the implantation of malignant tissue. For example, spillage of tumor cells probably occurs during resections of esophageal tumors because of the narrow margins afforded 


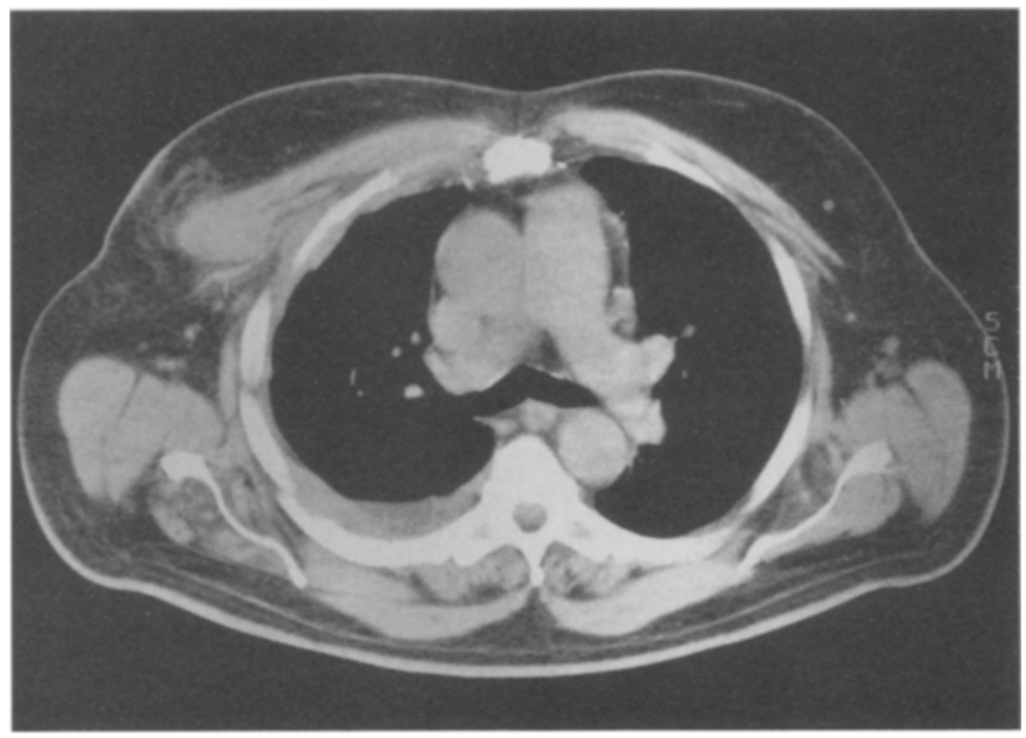

Fig. 2. Thoracic computed tomogram obtained 4 months after the operation, demonstrating a $3 \mathrm{~cm}$ mass under the right pectoralis major muscle in the region of the anterior thoracoscopy incision. An uncharacterized pleural effusion is present.

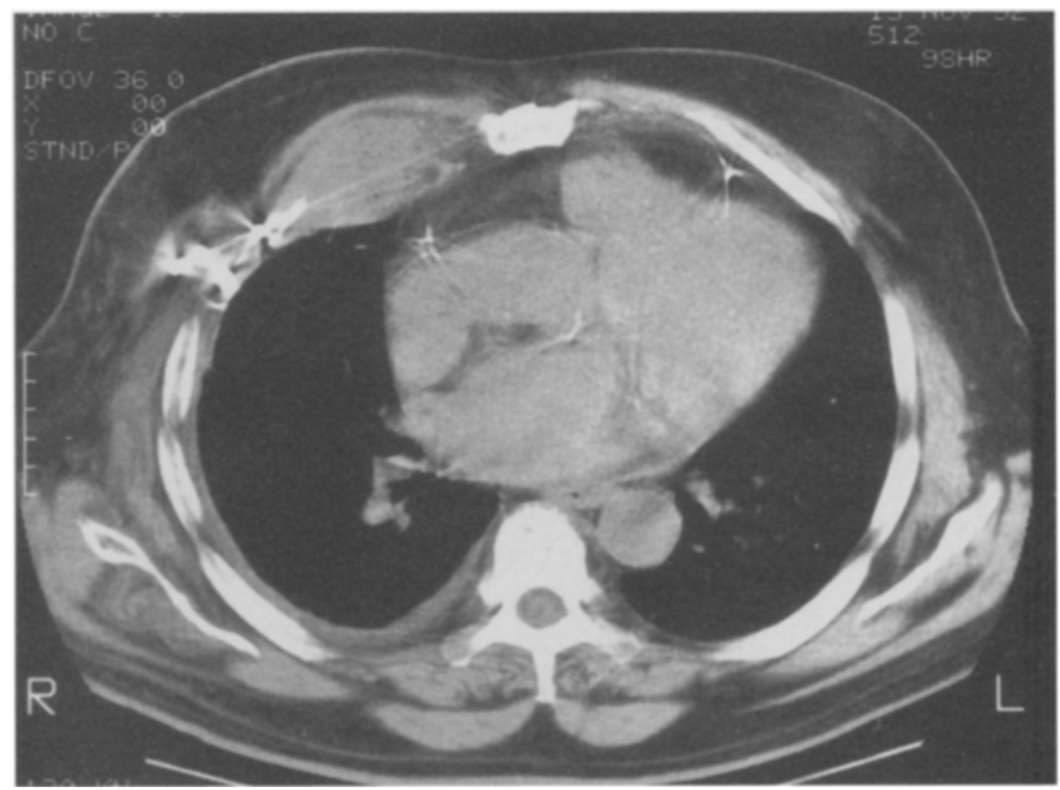

Fig. 3. Thoracic computed tomogram obtained 4 mouths after partial chest wall resection of recurrent tumor in the anterior thoracoscopy incision demonstrates second recurrence in the right anterior chest wall in the region between the prior chest wall resection and the sternum.

by the proximity of the aorta and the vertebral column. However, chest wall implants after esophagectomy for malignant disease are reported only rarely. ${ }^{11: 12}$

Mediastinoscopic biopsy of lymph nodes involved with metastatic disease often disrupts the node capsule. Despite isolated case reports of tumor growing within mediastinal incisions, ${ }^{13,14}$ a review by Aushbaugh ${ }^{15}$ reported mediastinoscopic tumor implantation in only eight of 6490 procedures $(0.1 \%)$. There are factors that may reduce the likelihood of incision implantation during mediasti- 


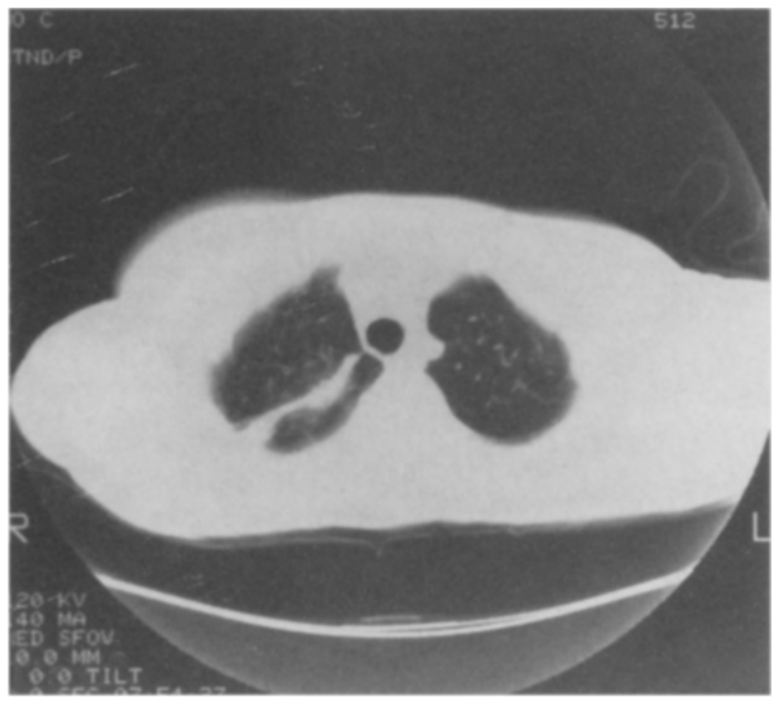

Fig. 4. Computed thoracic tomogram demonstrating recurrence of a sarcoma metastatic to the lung 8 weeks after thoracoscopic resection.

noscopy. Specimens are removed through the protective passage of the mediastinoscope, radiation may be given to the mediastinum, and the limited life expectancy of patients with disseminated lung cancer may limit the period during which implants could become apparent.

This report describes 21 cases in which thoracic malignant disease recurred along the margin of resection, on the pleural surface, or within the chest wall after VATS procedures. It is not intended to be an exhaustive recording of all of the potential cases of tumor implantations from VATS procedures over a 7-year period but rather a chronicling of some representative suggestive cases from surgeons experienced in VATS techniques. In fact, this was a voluntary reporting based on recollection and should be considered a collection of anecdotes. The denominator of the number of thoracoscopic procedures from which these cases are drawn is unknown. The total number of procedures performed by the members of the VATSSG is unknown. Some of the procedures reported were not performed by members of the VATSSG; the operations were performed by other surgeons at the same institution or else the patients were referred for postoperative consultation from other institutions. Finally, the burden for defining the recurrence as a consequence of intraoperative events was placed on the operating surgeon, a fact that would lead to a conservative report.
Some of the cases presented might not be considered complications of the VATS technique. Five cases involve mesothelioma. Because the propensity for such tumors to grow into thoracotomy and chest tube incisions is widely recognized, mesotheliomas should be considered separately from the other cases. Of the histologic types encountered, smallcell carcinoma of the lung and melanoma are aggressive enough that implantation can be expected. The preoperative diagnosis in one other case was pleural effusion (subsequently diagnosed as pulmonary adenocarcinoma), and it is possible that tumorladen fluid led to implantation in the thoracoscopy track. The remaining 13 cases are difficult to consider as complications to be expected after thoracic surgery. Furthermore, the interval between thoracoscopy and diagnosis of recurrence is sufficiently short to suggest a large inoculum of tumor cells, consistent with tumor disruption.

The thoracic medical and surgical community embraced VATS because of the rapid recuperation experienced by most patients. This is one of the phases that any new technique must go through. The second phase is recognition of the limitations of the technique with later appropriate application. ${ }^{16}$ However, a surgeon who is accustomed to performing lung resections through a thoracotomy may feel at a disadvantage when performing lung resections with VATS techniques. Current imaging techniques allow the operating surgeon to see only the visceral and parietal pleural surfaces of the thoracic cavity, with palpation of tissues limited to what can be reached by fingertips inserted between ribs. Ultrasonography has been advocated as an aid to image structures within the lung and mediastinal tissues, ${ }^{17}$ but for technical reasons it is unlikely that the images obtained will approach the sensitivity of direct bimanual palpation of the lung. To date, it is not clear whether the technical limitations of VATS technology will lead to an increased risk of sutureline recurrences or pleural or chest wall implants, because the available literature is limited to follow-up periods of 30 days only.

The technical problems that may be responsible for disruption of tumor appear to be twofold. First, pulling the tumor mass through relatively small incisions may deposit clumps of viable tumor cells in the chest wall. It is also possible that pleural implantation could result from attempts to pull a large mass through a small chest incision. Similar concerns have been voiced after observing seeding of laparoscopic surgical sites involving gall bladder 


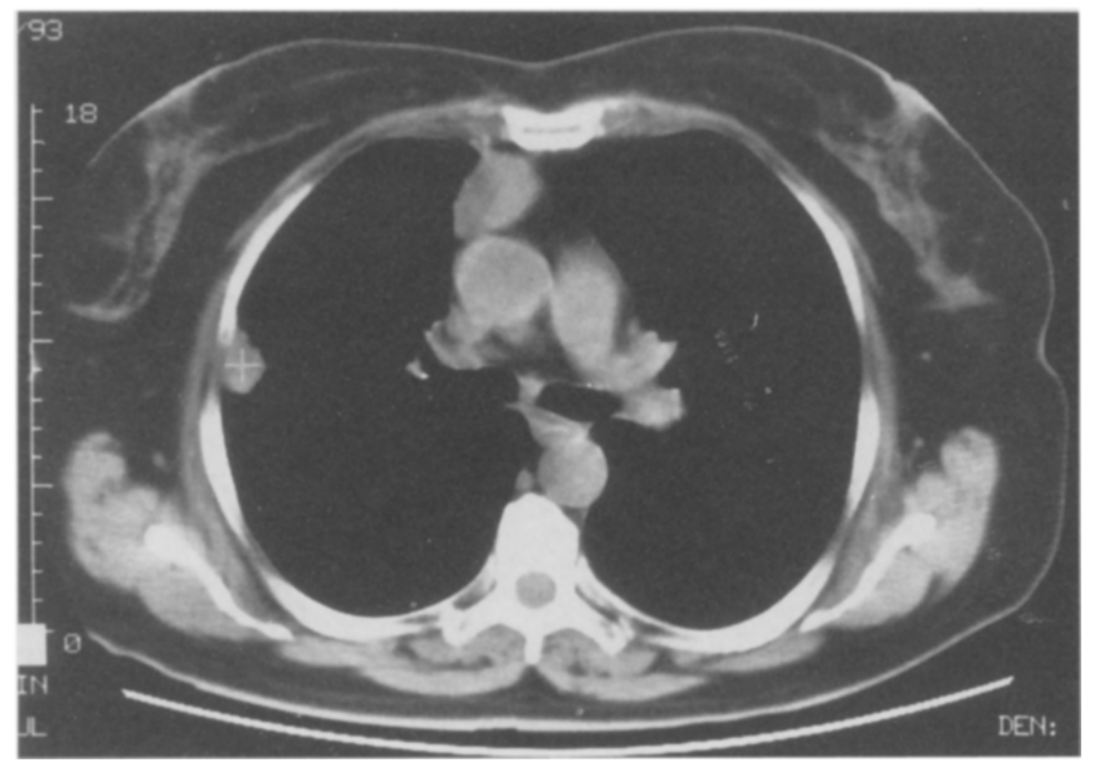

Fig. 5. Preoperative computed tomogram demonstrating a colon carcinoma metastatic to the right lung.

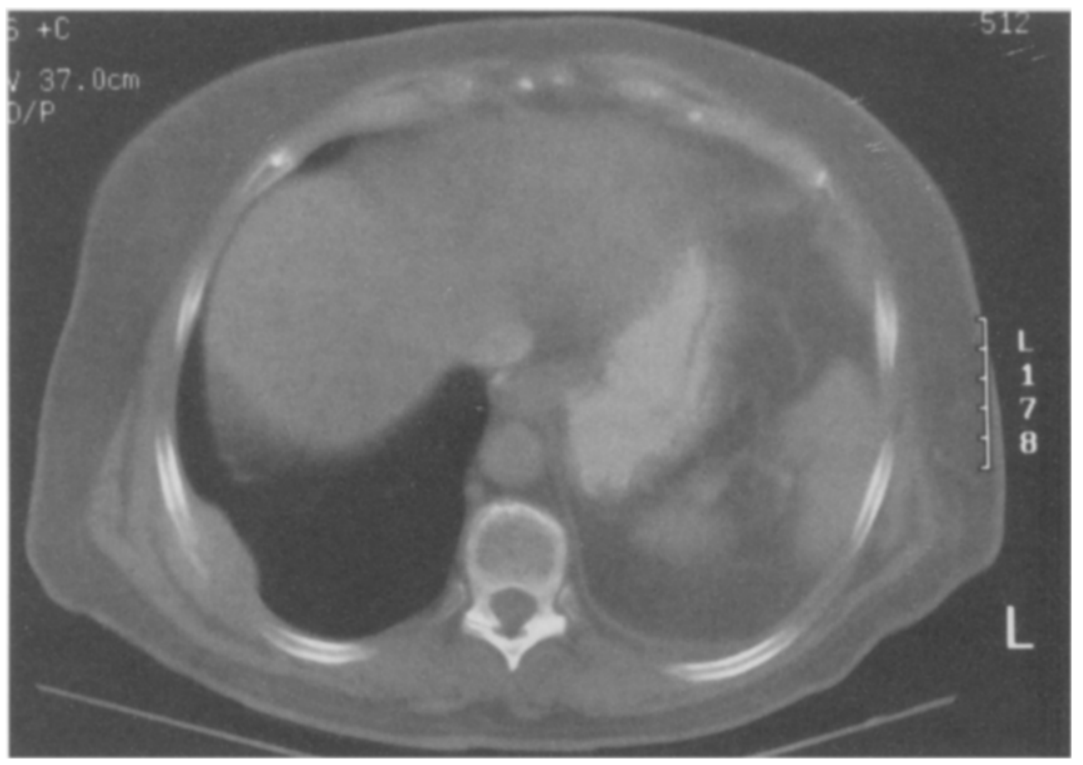

Fig. 6. Computed tomogram obtained 8 months after VATS resection of a metastatic colon carcinoma, demonstrating a right chest wall recurrence eroding a rib under a thoracoscopy port site.

carcinoma, ${ }^{18,19}$ hepatocellular carcinoma, ${ }^{20}$ gastric adenocarcinoma, ${ }^{21}$ and trophoblastic tissue ${ }^{22}$ and, most disturbingly, after laparoscopic colectomy for colonic adenocarcinoma. ${ }^{23}$ It has been suggested that specimens be placed within surgical gloves or special bags before extraction to protect against chest wall implantation during VATS procedures. ${ }^{1}$ Much as the mediastinoscope may offer some pro- tection against implantation during the biopsy of involved mediastinal lymph nodes, removing uncharacterized small biopsy specimens through plastic or metal ports inserted into the chest wall incisions may reduce the risk of seeding, but this has not been proved.

The cases in this report suggest that the more intractable problem may be disruption of the tumor 
at the time of removal from the lung parenchyma, leading to implantation either along the margin of resection or on the pleural surface. Pleural washing studies $^{9,10}$ performed during thoracotomy suggest that malignant cells are released into the pleural space during pulmonary resection. However, the fact that pleural or chest wall implants are rare after thoracotomy suggests that such microscopic deposits may be only marginally viable and may have little or no contact with the subcutaneous tissues. Current thoracoscopic techniques may lead to the deposition of larger, more viable clumps of tissue.

Critics of thoracoscopic techniques have already argued that thoracoscopic wedge excision of a lung cancer is an inadequate cancer operation and, should a malignant tumor be diagnosed during thoracoscopy, a thoracotomy and lobectomy should be performed. This recommendation is based on the multicenter trial of the Lung Cancer Study Group, which demonstrated that local recurrence was more frequent after wedge or segmental resection of stage I lung cancers. ${ }^{24}$ Before the widespread adoption of VATS procedures for the curative resection of intrathoracic malignant tumors, reports of long-term outcomes are needed.

\section{REFERENCES}

1. Landrenieau RJ, Hazelrigg SR, Ferson PF, et al. Thorascopic resection of 85 pulmonary lesions. Ann Thorac Surg 1992;54: 415-20.

2. Thurer RL. Video-assisted thoracic surgery. Ann Thorac Surg 1993;56:198-204.

3. LoCicero J. Video Assisted Thoracic Surgery Study Group. Ann Thorac Surg 1993;56:734-5.

4. Fry WA, Siddiqui A, Pensler JM, et al. Thoracoscopic implantation of cancer with a fatal outcome. Ann Thorac Surg 1995;59:42-5.

5. Migueres J, Jover A, Krempf M. Note sur les incidents et accidents de la biopsie pleurale a l'aiguille: l'ensemencement neoplasique de la paroi. Poumon Coeur 1975:31:347-9.

6. Nankhonya JM, Zakhour HD. Malignant seeding of needle aspiration tract: a rare complication. Br J Dermatol 1991; 124:285-6.

7. Voravud N, Shin DM, Dekmezian RH, Dimery I, Lee JS, Hong WK Implantation metastasis of carcinoma after percutaneous fine-needle aspiration biopsy. Chest 1992;102:313-5.
8. Sinner WN. Pulmonary neoplasms diagnosed with transthoracic needle biopsy. Cancer 1979;43:1533-40.

9. Buhr J, Berghauser K-H, Morr H, Dobroschke J, Ebner HJ. Tumor cells in intraoperative pleural lavage: an indicator for the poor prognosis of bronchogenic carcinoma. Cancer 1990; 65:1801-4

10. Okumura M, Ohshima S, Kotake Y, Morino H, Kikiu M, Yasumitsu T. Intraoperative pleural lavage cytology in lung cancer patients. Ann Thorac Surg 1991;51:599-604.

11. Haverback CZ, Smith RR. Transplantation of tumor by suture thread and its prevention. Cancer 1959;12:1029-42.

12. Recht MP, Coleman BG, Barbot DJ, et al. Recurrent esophageal carcinoma at thoracotomy incisions; diagnostic contributions of CT. J Comput Assist Tomogr 1989;13:58-60.

13. Sullivan WD, Passamonte PM. Mediastinoscopy incision site metastasis: response to radiation therapy. South Med J 1982;75:1428.

14. Rate WR, Solin LJ. Mediastinoscopy incision site metastasis: implications for radiotherapeutic treatment. Cancer 1989;63: 68-9.

15. Auschbaugh DG. Mediastinoscopy. Arch Surg 1970;100:56873.

16. LoCicero J. Critical evaluation of video assisted thoracic surgery. In: Kaiser LR, Daniel TM, ed. Thoracoscopic surgery. Boston, Little Brown, 1993:261-4.

17. Shennib H. Intraoperative localization techniques for pulmonary nodules. Ann Thorac Surg 1993;56:745-8.

18. Pezet D, Fondrinier E, Rotman N, et al. Parietal seeding of carcinoma of the gallbladder after laparoscopic cholecystectomy. Br J Surg 1992;79:230.

19. Drouard F, Delamarre J, Capron J-P. Cutaneous seeding of gallbladder cancer after laparoscopic cholecystectomy [Letter]. N Engl J Med 1991;325:1316.

20. Keate RF, Shaffer R. Seeding of hepatocellular carcinoma to peritoneoscopy insertion site. Gastrointest Endosc 1992;38: 203-4.

21. Cava A, Roman J, Gonzalez Quintela A, Martin F, Aramburo P. Subcutaneous metastasis following Iaparoscopy in gastric adenocarcinoma. Eur J Surg Oncol 1990;16:63-7.

22. Thatcher SS, Grainger DA, True LD, DeCherney AH. Pelvic trophoblastic implants after laparoscopic removal of a tubal pregnancy. Obstet Gynecol 1989;74(3 Pt 2):514-5.

23. Ngoi. In: Wexner SD. Laparoscopic resection of colorectal cancer. Contemp Surg 1995;46:93-111.

24. Ginsberg RJ. The comparison of limited resection to lobectomy for T1N0 non-small cell lung cancer: LCSG 821 . Chest 1994;106:3185-95. 